\title{
NILAI EKONOMI TRANSPORTASI UMUM BAGI MASYARAKAT PERKOTAAN
}

\section{ECONOMIC VALUE OF PUBLIC TRANSPORTATION FOR URBAN COMMUNITIES}

Sulistya Rini Pratiwi ${ }^{1}$, Meylin Rahmawati ${ }^{2}$, Yohanna Thresia Nainggolan ${ }^{3}$, M.Tharmizi Junaid ${ }^{3}$, Aan Digita Malik ${ }^{3}$

${ }^{1}$ Jurusan Ekonomi Pembangunan, Fakultas Ekonomi Universitas Borneo Tarakan

${ }^{2}$ Jurusan Manajemen, Fakultas Ekonomi Universitas Borneo Tarakan

${ }^{3}$ Jurusan Akuntansi, Fakultas Ekonomi Universitas Borneo Tarakan

sr.pratiwi@borneo.ac.id

\begin{abstract}
Abstrak : Tujuan dari penelitian ini adalah menganalisis nilai kemampuan membayar (Ability To Pay/ ATP) dan kesedian membayar (Willingness To Pay/WTP) masyarakat dalam hal ini pengguna untuk membayar jasa layanan angkutan umum, dengan menggunakan contingent valuation method. Dan mengidentifikasi variable yang berpengaruh terhadap ATP, WTP dan Pendapatan penyedia angkutan umum, menggunakan ordinary least square method. Hasil menunjukkan WTP atau tingkat kemauan membayar rata-rata tertinggi adalah responden yang mempunyai jenis pekerjaan PNS/TNI/POLRI, yaitu Rp.6.834,-Selain itu juga memiliki wtp rata-rata yang lebih tinggi (Rp.6.834,-) daripada wtp total (Rp. 5.540,39). Sedangkan nilai wtp terendah ada pada responden yang memiliki jenis pekerjaan sebagai pelajar/mahasiswa, yaitu Rp.4.250,-. Sedangkan ATP atau tingkat kemampuan membayar rata-rata tertinggi adalah responden yang telah pensiun, yaitu Rp.5.834,-. Dan yang paling rendah adalah Rp.2.262,ada pada responden yang memiliki jenis pekerjaan sebagai wiraswasta. Pendapatan (INC) berpengaruh positif tetapi tidak signifikan terhadap WTP, sedangkan Biaya Transportasi (COST) untuk angkutan umum berpengaruh negative signifikan terhadap WTP. Untuk model ATP, Pendapatan dan Biaya Transportasi berpengaruh positif tidak signifikan. Banyaknya penumpang dan jumlah jam kerja pengemudi berpengaruh positif terhadap tingkat pendapatan pengemudi. Namun hanya jumlah jam kerja yang signifikan, sedangkan jumlah penumpang tidak signifikan.
\end{abstract}

Kata kunci: ATP, WTP, Transportasi Darat, Pelayanan Publik 
Abstract: The purpose of this study was to analyze the value of the ability to pay (ATP) and willingness to pay (WTP) of the community, in this case the user to pay for public transport services, using the contingent valuation method. And identify variables that affect ATP, WTP and income of public transport providers, using the ordinary least square method. The results showed that the highest WTP or the level of willingness to pay is the respondent who has a civil servant/TNI/POLRI type of work, namely Rp.6,834 Besides that, it also has a higher average WTP (Rp.6,834,-)than the total WTP (Rp.5,540.39). Meanwhile, the lowest WTP value was in the respondent who has a type of work as a student, namely Rp.4,250,-. Meanwhile, the highest average ATP or ability to pay is respondents who have retired, namely Rp.5,834-. And the lowest was Rp.2,262,- is the respondent who has the type of work as an entrepreneur. Income (INC) has a positive but insignificant effect on PAPs, while Transportation Costs (COST) for public transportation have a significant negative effect on PAPs. For the ATP model, Transportation Revenue and Cost has a positive and insignificant effect. The number of passengers and the number of hours the driver works has a positive effect on the income level of the driver. However, only the number of hours worked is significant, while the number of passengers is not significant.

Keywords: ATP, WTP, Land Transportation, Public service

\section{PENDAHULUAN}

Transportasi merupakan suatu proses perpindahan suatu barang atau orang (penumpang) dari suatu tempat ke tempat lain. Dengan berpindahnya manusia dari satu tempat ke tempat lain melalui pengangkutan maka produktifitasnya akan bertambah tinggi. Karena memperoleh nilai tambah, maka pemilik barang maupun manusia (penumpang) bersedia memberikan balas jasa. Balas jasa sering disebut ongkos (tarif).

Keputusan Pemerintah untuk menaikkan harga bahan bakar minyak (BBM) secara langsung (tahap pertama) menambah beban biaya operasi kendaraan angkutan kota. Pada tahap kedua, biaya ini akan meningkat lagi dengan terjadinya peningkatan harga komponen dan sukucadang kendaraan bermotor. Di sisi lain, tariff angkutan kota masih ditetapkan oleh Pemerintah dan diupayakan untuk tidak naik dalam rangka memberikan pelayanan transportasi yang murah kepada masyarakat luas.

Dampak kenaikan minyak dunia yang mengakibatkan pemerintah mengurangi subsidi untuk minyak dalam negeri sehingga harus dinaikkannya harga bahan bakar minyak (BBM). Akibatnya 
secara langsung berdampak terhadap dinaikkan tarif angkutan kota. Dalam membuat kebijaksanaan tentang tarif ini pemerintah selalu memperhatikan kepentingan kedua belah pihak yang berkaitan dengan angkutan kota ini, pihak pertama yaitu para pengusaha sebagai pemilik dan pemegang kuasa terhadap kendaraan dan para supir sebagai pemberi jasa yang akan menerima pembayaran sesuai dengan tarif yang berlaku dan pihak kedua adalah masyarakat sebagai pengguna jasa yang akan membayar ongkos. Jika salah satu pihak merasa dirugikan, maka proses pelaksanaan kegiatan transportasi akan terganggu. Hal ini terlihat adanya aksi mogok dari para supir angkutan kota akibat penetapan tarif yang tidak sesuai atau merugikan para supir.

Sebagaimana di kota-kota lainnya, Kota Tarakan juga memiliki sistem trayek angkutan. Trayek angkutan adalah lintasan kendaraan kota atau rute untuk pelayanan jasa angkutan orang dengan mobil yang mempunyai asal dan tujuan perjalanan tetap, lintasan tetap dan jadwal tetap maupun tidak berjadwal.

Di sisi lain, transportasi kota mempunyai permasalahan yang lain. Rendahnya tingkat pelayanan yang diberikan oleh penyelenggara angkutan kota, maka pengguna jasa yang mempunyai pilihan, berpindah ke kendaraan pribadi.

Sehingga ketersediaan lebih besar dibandingkan dengan permintaan, menyebabkan pendapatan dari sektor jasa ini menurun dan tidak sebanding dengan biaya operasional kendaraan (BOK), yang berdampak pada makin turunnya tingkat pelayanan angkutan kota jalan.

Pada akhirnya secara makro menyebabkan biaya ekonomi tinggi akibat kemacetan, kecelakaan hingga kesehatan/lingkungan. Dalam pengembangan angkutan kota perlu diketahui besaran tingkat kemampuan membayar (ability to pay (ATP)) dan kemauan membayar (willingness to pay (WTP)). Dengan diketahuinya besaran tingkat kemampuan membayar ATP/WTP dapat digunakan untuk menetapkan besaran tarif layanan angkutan kota di Kota Tarakan. Mendasari hal tersebut maka perlu dilakukan kegiatan Studi ATP/WTP Masyarakat Pengguna Angkutan Kota dan Pendapatan Supir Angkutan Kota di Kota Tarakan. Hasil kajian dapat menjadi pertimbangan dalam pengembangan dan perencanaan transportasi wilayah di Kota Tarakan khususnya dalam menetapkan tarif angkutan kota.

\section{TINJAUAN PUSTAKA}

Menurut Raharjo (2010) adalah kegiatan pemindahan barang dan manusia dari tempat asal ke tempat tujuan, transportasi untuk 
memudahkan manusia dalam melakukan aktivitas sehari-hari.

Sedangkan Angkutan Kota sendiri mempunyai arti, yaitu pemindahan orang atau barang dari satu tempat ke tempat lain dengan menggunakan kendaraan yang disediakan untuk dipergunakan oleh kota dengan dipungut bayaran (Dishubdarat, 2012). Dampak negatif yang mungkin dapat terjadi dengan adanya transportasi yaitu, (Kamaludin, 2003):

1. Bahaya atas kehancuran umat manusia

2. Hilangnya sifat-sifat individual dan kelompok masyarakat

3. Frekuensi dan intensitas kecelakaan yang relatif lebih tinggi

4. Makin meningkatnya urbanisasi, kepadatan dan konsentrasi penduduk.

5. Hilang atau tersingkirnya industri kerajinan rumah tangga.

Dalam hal ini hubungan transportasi khususnya transportasi jalan raya, menjalankan fungsinya sebagai unsur penting yang melayani kegiatan- kegiatan yang sudah atau sedang berjalan atau the servicing finction dan sebagai unsur penggerak penting dalam proses pembangunan atau the promoting function (Kamaluddin, 2003).

Transportasi dapat diklasifikasikan menurut macam, atau jenisnya (mode of transportasion) yang lebih lanjut dapat ditinjau dari segi barang yang diangkut, dari daerah geografis transportasi ini berlangsung dan dari sudut teknis serta alat angkutnya, (Kamaluddin 2003);

1. Dari segi barang yang diangkut Dari segi barang yang diangkut, transportasi dapat diklasifikasikan atas :
a. Angkutan Penumpang (passengger)
b. Angkutan Barang (goods)
c. Angkutan Pos (mail).

2. Dari Sudut Geografis

Jika dilihat dari sudut geografis, Transportasi dapat dibagi sebagai berikut :
a. Antar pulau, misal dari Sumatra ke Jawa
b. Angkutan antar kota : dari Padang ke Bukit Tinggi
c. Angkutan antar daerah : dari Sumatra ke Riau.

3. Dari sudut teknis dan alat pengankutannya jalan raya atau higway Transportasion (Road Transportasion) seperti pengangkutan dengan menggunakan truk, bis dan sedan.

$\begin{array}{lll}\text { a. Pengangkutan Rel } & \text { (Rall } \\ \text { Transportasion) } & & \text { yaitu }\end{array}$ angkutan kereta api, trem dan sebagainya. Pengangkuatn jalan raya dan pengangkutan rel kadang-kadang keduanya digabung dalam golongan yang disebut Rail and Road Transportasion atau land 
Transportasion (transportasi darat).

b. Pengangkutan

(transportation

Udara

transportation)

angkutan

by air

yaitu

dengan

menggunakan kapal terbang.

Adapun golongan pemakai jasa

angkutan terbesar dalam masyarakat terdiri dari :

1. Perusahaan Industri, Perusahaan Perdagangan, dan lain sebagainnya.

2. Pemakaian Jasa angkutan dalam masyarakat Kota.

3. Pemakaian jasa dari pihak pemerintah (Goverment demand).

Dalam rangka pemanfaatan jasa- jasa angkutan agar diusahakan secara efesiensi dan memberikan pelayanan yang dioptimalkan kepada masyarakat pengguna jasa transportasi. Menurut Nasution (2008) bahwa transportasi sebagai kegiatan pemindahan barang dan manusia dari tempat asal ke tempat tujuan, dalam proses ini terdapat unsur- unsur berikut (1) adanya muatan yang diangkut, terdapatnya kendaraan sebagai sarana angkutannya, (3) adanya jalan yang dapat dilaluinya dan (4) tersedianya terminal asal dan terminal tujuan, serta (5) sumber daya manusia dan organisasi atau manajemen yang menggerakkan kegiatan transportasi tersebut.

Fungsi transportasi adalah untuk mengangkut penumpang dan barang dari suatu tempat ke tempat lain.

Kebutuhan akan angkutan penumpang tergantung fungsi bagi kegunaan seseorang (personal place utility). Seseorang dapat mengadakan perjalanan untuk kebutuhan pribadi atau untuk keperluan usaha (Salim, 2004).

Transportasi merupakan kegiatan jasa pelayanan (service activities). Jasa transportasi diperlukan untuk membantu kegiatan sektor-sektor lain (sektor pertanian, sektor perindustrian, sektor pertambangan, sektor perdagangan, sektor konstruksi, sektor keuangan, sektor pemerintahan, transmigrasi, pertahanan-keamanan dan ainnya) untuk mengangkut barang dan manusia dalam kegiatan pada masing-masing sektor tersebut. Oleh karena itu jasa transportasi dikatakan derived demand atau permintaan yang diderivasi atau turunan, artinya permintaan jasa transportasi bertambah karena diperlukan untuk melayani berbagai kegiatan ekonomi dan pembangunan yang meningkat.

Bertambahnya permintaan jasa transportasi adalah berasal dari bertambahnya kegiatan sektor-sektor lain. Sesuai sifatnya sebagai derived demand maka perencanaan sektor transportasi selalu mengandung ketidakpastian Menurut Siregar, (dalam Adisasmita, 2010).

Tarif angkutan merupakan biaya yang harus dibayar oleh pengguna jasa angkutan atas fasilitas 
yang diterima sesuai dengan harga yang dikeluarkan oleh operator yang menyediakan jasa angkutan tersebut.

Menurut undang- undang Lalu Lintas dan angkutan Jalan penetapan tarif angkutan kota harus melibatkan tiga pihak, yaitu:

1. Pengelola jasa angkutan kota sebagai pihak yang mengharapkan tarif dapat seimbang dengan jasa pelayanan yang diberikan.

2. Pengguna jasa angkutan kota sebagai pihak yang mengeluarkan biaya setiap kali menggunakan angkutan kota, dengan harapan memperoleh layanan yang baik dan nyaman.

3. Pemerintah sebagai pihak yang menentukan tarif resmi dan sebagai regulator yang menyeimbangkan kepentingan masyarakat pengguna dengan pengelola, tanpa mengesampingkan pendapatan asli daerah dari sektor transportasi.

Menurut Adisasmita (2010), dasar yang digunakan untuk menentukan tarif jasa angkutan untuk transportasi didasarkan salah satu dari dua cara berikut ini:

1. Sistem pembentukan tarif atas dasar nilai jasa transportasi (value of service pricing) dengan sistem ini tarif didasarkan atas nilai yang dapat cenderung menentukan tarif yang tertinggi) dan yang kedua mengikuti dasar cost of service pricing (yang cenderung menentukan tarif pada tingkat yang terendah).

2. Selain dari pada itu terdapat penentuan tarif charging what the traffic will bear (di mana tarif yang ditentukan akan berada di antara kedua titik yang terendah dan tertinggi tersebut). Untuk itu dasar tarif ini berusaha dapat menutupi seluruh biaya variabel sebanyak mungkin dan bagian dari biaya tetap (fixed cost).

Dalam perumusan tarif angkutan kota perkotaan disamping memperhatikan biaya operasi kendaraan juga harus memperhatikan daya beli atau kemampuan membayar dari pengguna jasa tersebut, dimana kemampuan tersebut merupakan kemauan berdasarkan persepsi pengguna (willingness to pay). Menurut Fauzi (2004), nilai ekonomi didefinisikan sebagai pengukuran jumlah maksimum seseorang ingin mengorbankan barang dan jasa untuk memperoleh barang dan jasa lainnya ini biasa disebut keinginan membayar (willingness to pay) seseorang terhadap barang dan jasa yang telah digunakannnya.

Willingness To Pay (WTP) adalah kesediaan pengguna untuk mengeluarkan imbalan atas jasa yang diperolehnya. Pendekatan yang dilakukan dalam analisis WTP didasrkan pada persepsi pengguna tarif dari jasa pelayanan angkutan kota tersebut. Dalam permasalahan transportasi WTP dipengaruhi oleh 
beberapa faktor, diantaranya adalah (Fauzi, 2004):

1. Produk yang ditawarkan/disediakan oleh operator jasa pelayanan transportasi; Kualitas dan kuantitas pelayanan yang disediakan;

2. Utilitas pengguna terhadap angkutan kota tersebut;

3. Perilaku pengguna.

Barang publik menurut Mangkoesoebroto (2001), tidak semua barang dan jasa yang ada dapat disediakan oleh sektor swasta. Barang dan jasa yang tidak dapat disediakan oleh sistem pasar ini disebut barang publik, yaitu barang yang tidak dapat disediakan melalui transaksi antara penjual dan pembeli.

Barang swasta adalah barang yang dapat disediakan melalui sistem pasar, yaitu melalui transaksi antara penjual dan pembeli. Adanya barang yang tidak dapat disediakan melalui sistem pasar ini disebabkan karena adanya kegagalan sistem pasar (market failure).

Sistem pasar tidak dapat menyediakan barang/jasa tertentu oleh karena manfaat dari adanya barang/jasa tersebut tidak hanya dirasakan secara pribadi akan tetapi dirasakan oleh orang banyak. Contoh dari barang/jasa yang tidak dapat disediakan melalui system pasar, misalnya saja jalan, pembersihan udara, listrik dari PLN, kehakiman, pekerjaan kota, dll.

\section{METODE PENELITIAN}

Penelitian ini dilakukan di Kota Tarakan, dengan menggunakan data primer dan data sekunder. Sampel yang digunakan didapatkan menggunakan kuesioner. Sampel dalam penelitian ini menggunakan beberapa kriteria yaitu: a). pengguna angkutan kota, b). pengemudi angkutan kota. Sampel yang digunakan sebanyak 149 orang, 100 pengguna dan 49 pengemudi. Dengan menggunakan contingent valuation method.

\section{HASIL DAN PEMBAHASAN}

\section{Analisis Tarif Berdasarkan Willingness To Pay /WTP dan Ability To Pay/ ATP}

Willingness to pay/ WTP digunakan untuk mengetahui tingkat kemauan membayar jasa angkutan kota oleh responden dalam hal ini adalah pengguna angkutan kota.

WTP atau tingkat kemauan membayar rata-rata tertinggi adalah responden yang mempunyai jenis pekerjaan PNS/TNI/POLRI, yaitu Rp.6.834,-. Selain itu juga memiliki wtp rata-rata yang lebih tinggi (Rp.6.834,-) daripada wtp total (Rp. 5.540,39). Sedangkan nilai wtp terendah ada pada responden yang memiliki jenis pekerjaan sebagai pelajar/mahasiswa, yaitu Rp.4.250,-. 
Tabel 1. Tabulasi Jumlah Responden Berdasarkan WTP Dan Pekerjaan

\begin{tabular}{|c|c|c|c|c|c|c|c|}
\hline \multirow[t]{2}{*}{ Pekerjaan } & \multicolumn{4}{|c|}{ Willingness To Pay (Rp) } & \multirow[t]{2}{*}{ Total } & \multirow{2}{*}{$\begin{array}{c}\text { WTP } \\
\text { Rata- rata }\end{array}$} & \multirow{2}{*}{$\begin{array}{l}\text { WTP TOTAL } \\
\text { RATA-RATA }\end{array}$} \\
\hline & 3.000 & 5.000 & 6.000 & 7.000 & & & \\
\hline Pelajar/mahasiswa & 3 & 5 & - & - & 8 & Rp.4.250,- & \multirow{6}{*}{ Rp. 5.540,3 } \\
\hline Ibu Rumah Tangga & - & 13 & 10 & 0 & 23 & Rp.5.435,- & \\
\hline Wiraswasta & 2 & 26 & 20 & 6 & 54 & Rp.5.519,- & \\
\hline PNS/TNI/POLRI & - & - & 1 & 5 & 6 & Rp.6.834,-- & \\
\hline Pegawai swasta & - & - & 2 & 4 & 6 & Rp.6.667,- & \\
\hline Pensiunan & - & 2 & 1 & - & 3 & Rp.5.334,-- & \\
\hline TOTAL & 5 & 46 & 34 & 15 & 100 & & \\
\hline
\end{tabular}

Sumber: Data Primer, 2019

Table 2. Tabulasi Jumlah Responden Berdasarkan ATP Dan Pekerjaan

\begin{tabular}{|c|c|c|c|c|c|c|c|c|c|}
\hline \multirow[t]{2}{*}{ Pekerjaan } & \multicolumn{3}{|c|}{$\begin{array}{c}\text { Proporsi Biaya Angkutan } \\
\text { Kota (Rp) }\end{array}$} & \multicolumn{5}{|c|}{ Frekuensi } & \multirow[t]{2}{*}{ ATP } \\
\hline & 15.000 & 22.500 & Rata-rata & $\begin{array}{c}3 \\
\text { kali }\end{array}$ & $\begin{array}{c}5 \\
\text { kali }\end{array}$ & $\begin{array}{c}8 \\
\text { kali }\end{array}$ & $\begin{array}{l}15 \\
\text { kali }\end{array}$ & $\begin{array}{c}\text { Rata- } \\
\text { rata }\end{array}$ & \\
\hline $\begin{array}{l}\text { Pelajar/ } \\
\text { mahasiswa }\end{array}$ & 8 & - & Rp.15.000,- & 8 & - & - & - & 3 & Rp.5.000,- \\
\hline $\begin{array}{l}\text { Ibu Rumah } \\
\text { Tangga }\end{array}$ & 20 & 3 & Rp.15.979,- & 17 & 6 & - & - & 4 & Rp.3.995,- \\
\hline Wiraswasta & 48 & 6 & Rp.15.834,- & 9 & 28 & 8 & 9 & 7 & Rp.2.262,- \\
\hline $\begin{array}{l}\text { PNS/TNI/POL } \\
\text { RI }\end{array}$ & 6 & - & Rp.15.000,- & 6 & - & - & - & 3 & Rp.5.000,- \\
\hline Pegawai swasta & 5 & 1 & Rp.16.250,- & 3 & 1 & 1 & 1 & 7 & Rp.2.322,- \\
\hline Pensiunan & 2 & 1 & Rp.17.500,- & 3 & - & - & - & 3 & Rp.5.834,- \\
\hline
\end{tabular}

Sumber: Data Primer, 2019

ATP atau tingkat kemampuan membayar rata-rata tertinggi adalah responden yang telah pensiun, yaitu Rp.5.834,-. Dan yang paling rendah adalah Rp.2.262,- ada pada responden yang memiliki jenis pekerjaan sebagai wiraswasta.

Hasil Analisis Regresi Willingness To Pay/ WTP dan Ability To Pay/ATP

Hasil analisis regresi linier berganda (ordinary least
square/OLS) terhadap kemauan membayar (willingness to pay/ WTP) dan kemampuan membayar (ability to pay/ATP) jasa angkutan kota masyarakat dan variabel yang mempengaruhinya (pendapatan dan biaya transportasi untuk angkutan kota) ditunjukkan oleh persamaan regresi berganda (persamaan 3 untuk WTP, dan persamaan 4 untuk ATP) sebagai berikut: 
$\mathrm{WTP}=\beta_{0}+\beta_{1} \mathrm{INC}+\beta_{2} \operatorname{COST}+\varepsilon$
$\mathrm{ATP}=\beta_{0}+\beta_{1} \mathrm{INC}+\beta_{2} \operatorname{COST}+\varepsilon$

$\mathrm{LOG}(\mathrm{WTP})=8.96+0.08 \mathrm{LOG}(\mathrm{INC})$ $-0.15 \mathrm{LOG}(\mathrm{COST})$ 3

\section{LOG(ATP) $\quad=15.87+$ $0.25 \mathrm{LOG}$ (INC) $\quad-1.17 \mathrm{LOG}(\mathrm{COST})$ 4}

Berdasarkan hasil perhitungan tersebut, maka hasil koefesien regresinya dapat di interpretasi sebagai berikut :

1. Nilai konstanta $\left(\alpha_{0}\right)=8,96$ dapat diartikan bahwa apabila semua variabel bebas (pendapatan dan biaya transportasi untuk angkutan kota) dianggap konstan atau tidak mengalami perubahan maka besarnya WTP mempunyai nilai sebesar 8,96 satuan.

2. Nilai konstanta $\left(\alpha_{0}\right)=15,87$ dapat diartikan bahwa apabila semua variabel bebas (pendapatan dan biaya transportasi untuk angkutan kota) dianggap konstan atau tidak mengalami perubahan maka besarnya ATP mempunyai nilai sebesar 15,87 satuan.

3. Nilai koefesien $\beta_{1}=0,08$ artinya jika pendapatan (INC) naik sebesar satu satuan maka WTP akan naik sebesar 0,08 satuan, dengan asumsi variabel independen lainnya konstan.
Artinya, setiap kenaikan pendapatan sebesar Rp.10.000,-, maka kemauan membayar responden naik sebesar Rp.800,-.

4. Nilai koefesien $\beta_{1}=0,25$ artinya jika pendapatan (INC) naik sebesar satu satuan maka ATP akan naik sebesar 0,25 satuan, dengan asumsi variabel independen lainnya konstan. Artinya, setiap kenaikan pendapatan sebesar Rp.10.000,-, maka kemampuan membayar responden naik sebesar Rp.2.500,--

5. Nilai koefesien $\beta_{2}=-0,15$ artinya jika biaya transportasi untuk angkutan kota (COST) naik sebesar satu satuan maka WTP akan turun sebesar 0,15 satuan, dengan asumsi variabel independen lainnya konstan. Atau dapat dikatakan bahwa, setiap kenaikan biaya transportasi untuk angkutan kota sebesar Rp.10.000,- akan menurunkan kemauan membayar responden sebesar Rp.1.500,-.

6. Nilai koefesien $\beta_{2}=-1,17$ artinya jika biaya transportasi untuk angkutan kota (COST) naik sebesar satu satuan maka ATP akan turun sebesar 1,17 satuan, dengan asumsi variabel independen lainnya konstan. Atau dapat dikatakan bahwa, setiap kenaikan biaya transportasi untuk angkutan kota sebesar Rp.10.000,- akan menurunkan kemampuan 
membayar responden sebesar Rp.11.700,-.

\section{Uji Model Secara Simultan}

Dalam penelitian ini variabel independen yang digunakan sebanyak dua (2) variabel. Berdasarkan hasil pengujian model secara simultan yang ada dalam model WTP, ternyata nilai F statistic adalah sebesar 4,514 dengan $\mathrm{p}$ - value $=0,013$, sehingga $\mathrm{p}$-value $<\alpha=0,05$. Berdasarkan hasil ini maka Ho ditolak, hasil tersebut menunjukkan bahwa variabel independent tidak berpengaruh secara simultan.

Sedangkan nilai $F$ statistik pada model ATP adalah sebesar 13,13 dengan $\mathrm{p}$-value sebesar 0,000 yang lebih besar dari nilai $\alpha(10 \%)$. Berdasarkan hasil tersebut, variable bebas pada model ATP berpengaruh secara simultan.

\section{Uji Model Secara Parsial}

Hasil regresi mengungkapkan bahwa secara keseluruhan, variable independen memiliki pengaruh yang tidak signifikan.

\section{Uji terhadap Koefesien Determinasi $\left(\mathbf{R}^{2}\right)$}

Besarnya koefesien determinasi $\left(\mathrm{R}^{2}\right)$ yang diperoleh pada model WTP adalah sebesar 0,085 (8,5\%), sedangkan untuk model ATP $0,213 \quad(21,3 \%)$. Hal ini menunjukkan bahwa variasi variabel independen yang digunakan dalam penelitian ini, yaitu pendapatan dan biaya transportasi untuk angkutan kota hanya dapat menjelaskan variasi variabel WTP sebesar 8,5\% dan $21,3 \%$, sedangkan $91,5 \%$ dan $78,7 \%$ dijelaskan oleh variabel lain yang tidak dimasukkan ke dalam model penelitian ini. Namun demikian meskipun nilai $\mathrm{R}$ square yang diperoleh dari hasil analisis ini rendah bukan berarti hasil penelitiannya tidak bagus. Menurut Gujarati (2004) Winarno (2009) Hill et al (2011) Widarjono (2013), bahwa nilai $\mathrm{R}$ Square yang tinggi adalah baik tetapi apabila diperoleh nilai R Square yang rendah bukanlah berarti hasil penelitian tersebut tidak baik.

\section{Uji Asumsi Klasik}

\section{Uji Multikolinieritas}

Dari hasil pengujian, maka kedua model tersebut ditemukan adanya multikolinearitas. Hal ini ditunjukan oleh koefisien determinasi regresi auxiliary lebih besar dari pada $\mathrm{R}^{2}$ regresi variabel utama. Namun demikian estimator yang BLUE tidak memerlukan asumsi terbebas dari masalah Multikolinearitas. Estimator BLUE hanya berhubungan dengan asumsi tentang variabel gangguan (Gujarati, 2004; Widarjono, 2013), sehingga indikasi multikolinearitas dapat diabaikan saja. Masalah 
multikolinearitas biasanya juga timbul karena mempunyai jumlah observasi yang sedikit.

\section{Uji Heteroskedastisitas}

Berdasarkan hasil analisis yang telah dilakukan dengan menggunakan uji white, pada model WTP diperoleh nilai p-value obs*square > a $(0,7780>0,05)$ maka disimpulkan tidak adanya heteroskedastisitas. Sedangkan pada model ATP diperoleh nilai p-value obs*-square $>$ a $(0,000<0,05)$, maka pada model ATP terindikasi penyakit heteroskedastisitas.

\section{Uji Autokorelasi}

Pengujian autokorelasi dalam persamaan diatas sudah dilakukan dengan uji serial correlation LM. Pada model WTP diperoleh nilai $\mathrm{p}$ value obs*-square $<$ a $(0,00<0,05)$ maka disimpulkan bahwa model WTP terindikasi autokorelasi. Untuk model kedua, yaitu model ATP diperoleh nilai $\mathrm{p}$-value obs*-square $>$ a $(0,2290>0,05)$ maka disimpulkan tidak adanya autokorelasi.

\section{Hasil Analisis Regresi Pendapatan Pengemudi}

Hasil analisis regresi selanjutnya adalah analisis model pendapatan supir angkutan kota (Inc). Variabel bebas yang dianalisis adalah jumlah penumpang (Pass) dan jumlah jam kerja (Hours).
$\mathrm{INC}=\beta_{0}+\beta_{1}$ PASS $+\beta_{2}$ HOURS + $\varepsilon$

5

$\mathrm{LOG}(\mathrm{INC})=12.86+0.32 \mathrm{LOG}$ $(\mathrm{PASS})+0.14 \mathrm{LOG}$ (HOURS) 6

Berdasarkan hasil perhitungan tersebut, maka hasil koefesien regresinya dapat di interpretasi sebagai berikut :

1. Nilai konstanta $\left(\alpha_{0}\right)=12,86$ dapat diartikan bahwa apabila semua variabel bebas PASS (jumlah penumpang) dan HOURS (jumlah jam kerja) dianggap konstan atau tidak mengalami perubahan maka besarnya INC (pendapatan) mempunyai nilai sebesar 12,86 satuan.

2. Nilai koefesien $\beta_{1}=0,32$ artinya jika jumlah penumpang (Pass) naik sebesar satu satuan maka Inc akan naik sebesar 0,32 satuan, dengan asumsi variabel independen lainnya konstan. Artinya, setiap kenaikan jumlah penumpang sebesar $100 \%$, maka pendapatan pengemudi sebesar $32 \%$.

3. Nilai koefesien $\beta_{2}=0,14$ artinya jika jam kerja (Hours) naik sebesar satu satuan maka Inc akan naik sebesar 0,14 satuan, dengan asumsi variabel independen lainnya konstan. Atau dapat dikatakan bahwa, setiap kenaikan $100 \%$ jumlah 
jam kerja akan meningkatkan pendapatan pengemudi sebesar $14 \%$.

\section{Uji Model Secara Simultan}

Dalam penelitian ini variabel independen yang digunakan sebanyak dua (2) variabel. Berdasarkan hasil pengujian model secara simultan, nilai $F$ statistic adalah sebesar 5,902 dengan p-value $=0,05$, sehingga $\mathrm{p}$-value $<\alpha=10 \%$. Berdasarkan hasil ini maka Ho diterima, hasil tersebut menunjukkan bahwa variabel independent berpengaruh secara simultan.

\section{Uji Model Secara Parsial}

Hasil regresi mengungkapkan bahwa secara keseluruhan, variable independen memiliki pengaruh yang tidak signifikan dan signifikan.

\section{Uji Asumsi Klasik}

\section{Uji Multikolinieritas}

Hasil analisis yang telah dilakukan berkaitan dengan uji ini disajikan dalam tabel. Pada model ini lolos uji multikolinearitas, karena nilai $\mathrm{R}$ square model utama lebih kecil daripada $\mathrm{R}$ square model variabel

Tabel 3. Hasil Uji Metode Klien

\begin{tabular}{|c|c|c|}
\hline Variabel Independen & $\begin{array}{c}\text { Nilai R } \mathbf{R}^{\mathbf{2}} \text { Model } \\
\text { Utama }\end{array}$ & $\begin{array}{c}\text { Nila } \\
\mathbf{R}^{\mathbf{2}} \text { antar Variabel } \\
\text { Independen }\end{array}$ \\
\hline INC & 0,20 & 0,332 \\
\hline COST & 0,20 & 0,22 \\
\hline
\end{tabular}

Sumber; Data Diolah, 2019.

\section{Uji Heteroskedastisitas}

Berdasarkan hasil analisis yang telah dilakukan dengan menggunakan uji white, pada model ini lolos uji heteroskedastisitas. Nilai p-value obs*- square > a $(0,03>$ $10 \%)$.

\section{Uji Autokorelasi}

Pengujian autokorelasi dalam persamaan diatas sudah dilakukan dengan uji serial correlation LM. Pada model WTP diperoleh nilai pvalue obs*-square $>$ a $(0,07>0,05)$ maka disimpulkan bahwa model WTP tidak terindikasi autokorelasi.

\section{SIMPULAN}

1. WTP atau tingkat kemauan membayar rata-rata tertinggi adalah responden yang mempunyai jenis pekerjaan PNS/TNI/POLRI, yaitu Rp.6.834,-. Selain itu juga memiliki wtp rata-rata yang lebih tinggi (Rp.6.834,-) daripada wtp total (Rp. 5.540,39). Sedangkan 
nilai wtp terendah ada pada responden yang memiliki jenis pekerjaan sebagai pelajar/mahasiswa, yaitu Rp.4.250,-. Sedangkan ATP atau tingkat kemampuan membayar rata-rata tertinggi adalah responden yang telah pensiun, yaitu Rp.5.834,-. Dan yang paling rendah adalah Rp.2.262,ada pada responden yang memiliki jenis pekerjaan sebagai wiraswasta.

2. Pendapatan (INC) berpengaruh positif tetapi tidak signifikan terhadap WTP, sedangkan Biaya Transportasi (COST) untuk angkutan umum berpengaruh negative signifikan terhadap WTP. Untuk model ATP, Pendapatan dan Biaya Transportasi berpengaruh positif tidak signifikan.

3. Banyaknya penumpang dan jumlah jam kerja pengemudi berpengaruh positif terhadap tingkat pendapatan pengemudi. Namun hanya jumlah jam kerja yang signifikan, sedangkan jumlah penumpang tidak signifikan.

\section{DAFTAR PUSTAKA}

Adisasmita, Rahardjo, 2010. DasarDasar Ekonomi Transportasi. Graha Ilmu, Yogyakarta.

Aspiani. 2003. Analisis Nilai Ability To Pay (ATP) Dan
Willingness To Pay (WTP)

Angkutan Ojek Pada

Kompleks Perumahan Di

Kota Makassar, Simposium FSTPT VI, Universitas Hasanuddin, Makasar.

Astuti, Pudji Dan Tertia, Vania. 2015. Study Of Ability To Pay And Willingness To Pay For Passanger Of Commuter Line Jakarta-Bogor. Proceeding 8 International Seminar On Industrial Engineering And Management. ISSN : 1978$774 \mathrm{x}$.

Eboli, L Dan, G. Mazzulla. 2008. Willingness-To-Pay Of Public Transport Users For Improvement In Service Quality. European Transport. 38 (2008): 107-118.

Fauzi, Akhmad. 2004. Ekonomi Sumber Daya Alam Dan Lingkungan Teori Dan Aplikasi. PT. Gramedia Pustaka Utama, Jakarta.

Fitrianingsih A Dan Paramitarani K. 2004. Kesediaan Dan Kemampuan Penumpang Kereta Api "Pandawangi", Laporan Tugas Akhir Jurusan Teknik Sipil (Tidak Dipublikasikan), Universitas Katolik Soegijapranata, Semarang.

Golub, Aaron David. 2003. Welfare Analysis Informal Transit Services In Brazil And The 
Effects Of Regulation.

Dissertation.

University Of California,

Berkeley.

Http:/Www.Uctc.Net/Resear

ch/Dis s108.Pdf. Diakses

Tanggal 28 Juli 2016.

Greene, William.H, 2000,

Econometric Analysis,

Macmillan Publishing

Company, New York.

Hotmaida, B. 1999. Analisis Ability

To Pay Dan Willingness To

Pay Tarif Angkutan Umum

Kota (Studi Kasus :

Kotamadia Medan), Tesis

Magister, Bidang Khusus

Rekayasa Transportasi

Program Magister Teknik

Sipil Program Pasca Sarjana

ITB (Tidak

Dipublikasikan), Bandung.

Mangkoesoebroto, Guritno. 2001.

Ekonomi Publik. BPFE,

Yogyakarta. Phanikumar, C.

V. And Maitra, Bhargab.

2006. Valuing Urban Bus

Attributes: An Experience In

Kolkata, Indian Institute Of

Technology. Journal Of

Public Transportation, Vol. 9,

No. 2, 2006.

Salim, Abbas. H. A. 2004.

Manajemen Transportasi. Pt

Raja Grafindo Persada.

Schwarzlose, Alicia A. Israel. Et.

All. 2014. Willingness To

Pay For Public

Transportation Options For

Improving The Quality Of
Life Of The Rural Elderly. Transportation Research Part A: Policy And Practice. Volume 61, March 2014, Pages 1-14.

Setijowarno, Abadi Dan

Sudaryatmo. 2005. Fakta

Kebijakan Transportasi

Publik Di Indonesia, Yayasan

Lembaga Konsumen

Indonesia (YLKI), Penerbit

Universitas Katolik

Soegijapranata, Semarang.

Worku, Genanew Bekele. 2013.

Demand For Improved Public

Transport Services In The UAE: A Contingent Valuation Study In Dubai, International Journal Of Business And Management; Vol. 8, No. 10; 2013. Issn 1833-3850 E-ISSN 18338119. Published By Canadian Center Of Science And Education. 